\title{
Social Mobilization and Communication Training Models for Community Groups in Nigeria
}

\author{
Femi Onabajo \\ Department of Mass Communication, University of Lagos, Lagos, Nigeria
}

KEYWORDS Information; dissemination; development; planning; implementing

ABSTRACT This paper examined the concept of social mobilization and guidelines that should be followed in social mobilization programming. It considered issues involved in information dissemination and what should be borne in mind in the designing of development messages. The paper also drew attention to communication training models which are hinged on radio study groups that could be adopted for the mobilization of Nigerians for social development. It recommended an appropriate strategy for planning and implementing effective social mobilization. which should employ a multi media campaign approach.

\section{INTRODUCTION}

Mobilization is the act of rallying for a purpose. It implies gathering people together for service. According to Okafor (2003) mobilization can be understood as a process of achieving a goal through a properly articulated group action.

In any sphere of human endeavour where development is the goal, it is necessary to assign communication a central role. To Umar (2003). communication can be likened to nerves in human physiology where it seeks to ensure effective linkage and harmonious actions in any social activity. Development communication as a concept has the tendency to rely heavily on interpersonal and mediated communication strategies in an effort to achieve meaningful but accelerated development. It has been argued by Clark (2001) that the usual top-down vertical flow of development information has informed most development approaches and this has accounted for most failures of the past. Hence there is the need to adopt horizontal and participatory approaches to social mobilization.

According to Rosengnen (2000) communication may take place between units of very different size and complexity and may occur between and within individuals, groups, organizations, social classes, nations and regions of the world. However the character of communication varies with the size and complexity of the communicating units as well as the distance in space and time between them. Over the centuries human beings have used various media to communicate. As new media for communication are created. old ones have become spe- cialized, but none has been completely abandoned.

Every individual weather poor or rich and irrespective of his religion or where he comes from (rural or urban dweller) has a right to be part of decision-making regarding his development. This action which is community based must involve the active collaboration between communicators and community leaders and the information being passed across should motivate, persuade and enlighten every community about the planned innovation. Communicators as catalysts should ensure an open and reconciliatory dialogue with active participation of the common man, the middle income and the priviledged by assigning contributory roles to leadership of each community, associations or groups representing various interests in the communities, traditional rulers and social institutions represented by schools, churches and mosques.

\section{WHY SOCIAL MOBILIZATION?}

According to Opubor (1985), many African nations are poor and underdeveloped, and cannot provide the basic necessities of life for their citizens. They lack the financial base and administrative capability to build the necessary infrastructure and to support the development and growth of a modern nation. Some of the attendant development problems include high rate of illiteracy, inadequate medical facilities, high birth rate, high infant mortality, high population growth rate and the political will to implement various national development programmes. 
Despite the attempts made by sympathetic foreign governments and international organizations to support and fund many social development programmes in Africa, not much have been achieved. Why social change is desirable, social development programmes can easily run into problems if they are not effectively communicated to the people. Employing western method of mobilizing Africans have been found to be defective. Also the conceptualization of development as that of building modern expressways, bridges, skyscrapers, provision of internet services, computerization and other white elephant projects, have not been effective in changing the basic attitudes of a significant percentage of the Nigerian population towards life.

The primary aim of social mobilization is to aid rural and urban development and such development is aimed at the poor and underpriviledged who have been marginalized over the decades. In terms of programme orientation to remedy the situation, Onabajo (2002) submits that development should entail interventions aimed at improved productivity, increased employment and commensurate incomes for the target groups as well as the provision of acceptable levels of food. shelter, education. health and housing. According to Akeredolu-Ale (1993), development especially that which concerns our rural areas should be aimed at the entire rural sector, even if it entails constituent programmes aimed at particular target groups. Such social mobilization programmes embarked on, should aim at rural transformation and also the transformation of the relationships between the rural and urban sectors of the economy.

Past development efforts in Nigeria have been preoccupied with the promotion of an urbanbased strategy of building a modern sector aimed at stimulating economic growth. While some achievements may have been recorded in this direction. the unfortunate consequence has been a neglect of the rural sector and its growth potentials. with the attendant effect of worsening rural poverty.

Rural stagnation, and to some extent rural decline in the provision of health facilities, agricultural production, employment opportunities, population control etc have adversely affected the growth-performance of the so-called modern sector, thus stifling the overall economic growth and national development efforts. Also, the failure to transform the rural areas, where the vast majority of our people live in terms of its productive capacity, income levels and quality of life. has had a number of particularly significant consequences in the following areas:

i. The retardation of modern-sector growth;

ii. The heightening of Nigeria's dependence on the outside world. even for food;

iii. The deepening of the poverty of the rural people and the urban poor; hence the marginalisation and impairment of morale among these large sectors of Nigeria's human resources;

iv. The escalation of social problems. e.g. unemployment. indecent and unjust levels of inequality, and an aggravation of the suffering of the most vulnerable groups in society. crime. social discontent and other tendencies characteristic of a deeply frustrated and demoralized society; and

v. The major economic and social crises in which Nigeria now finds herself.

Against this background, it is easy to see why the transformation of our rural areas is indeed a critical precondition for the rehabilitation of the national economy and to understand the sense in which many have argued that rural development, is in our particular circumstances, the foundation of national rehabilitation and development.

\section{GUIDELINES FOR SOCIAL MOBILIZATION PROGRAMMING}

According to Koinyan (1993). the following guidelines must be kept in constant view when development programmes are being conceptualized.

(i) That the programme package must take into consideration the view that development is a total package comprising socio-political, socio-cultural and socio-economic aspects, each with its own intricate requirements. As a total package, all the three major aspects of true development and their intricate requirements must be brought together.

(ii) That rural development is the foundation for national development, and therefore, that there should be no aspect of national development that should not have a building block or firm root in rural development.

(iii) That while economic growth should be pursued with all vigour. that real economic development as it deals with the quality of life 
and standard of living of the majority is most compelling, since in the final analysis, what really matters is how better off the majority really is.

(iv) That rural development programmes must be designed for mass grassroots participation. That all official paternalistic tendencies be curbed and the people orientated to act decisively as equal partners in the entire development process.

(v) That every effort be made to ensure that all resources allocated to all development programmes be used to achieve maximum effect and in the best interest of the majority.

(vi) That each and everyone of the country's over 100,000 communities can be made a real centre of growth and development, participating effectively even now in both primary and secondary production.

\section{ISSUES IN INFORMATION DISSEMINATION}

The following issues which significantly affect public information dissemination are worth discussing. They include:

(i) Access (ii) Exposure (iii) Content (iv) Education

1. Access: This refers to the physical existence of newspaper. radio. television or other mass media within reasonable range of the potential audience. In the rural areas, this might be an individual access to a private radio, or television; a situation may also be created where individuals have access through the establishment of community listening and viewing centres.

2. Exposure: Exposure is more complicated than access, because it deals not only with whether a person is within physical range of the particular mass medium. but also whether that person is actually exposed to the message. Exposure is hearing, seeing, reading or more generally experiencing. with at least a minimal amount of interest to the mass media message. This exposure might occur at an individual or group level.

3. Content: The content of a radio or television programme is usually designed with a particular audience in mind. Content can be broken down in various ways: information, entertainment programmes, music, news, sports, etc. These categories can obviously be broken down further into sub-types and production sources. An important distinction should also be made between commercial programming and purposive social change programming. The audience and kinds of programmes might be very different in these two types of programming structure. Information outcomes are the cognitive, affective, and attitudinal consequences of the audience access and exposure, to and comprehension of the media content. The previous review of research has indicated that even when lower socio economic groups have sufficient levels of access and exposure, the irrelevance of content will reduce levels of exposure in a kind of self regulating fashion. Research has shown that a major reason why some people learn more than others from the broadcast media is the self-selective nature of the audience. Although all groups may have access, those that are better off are more likely to take advantage of the information available.

4. Education: It is sometimes thought of as training in how to process a wider spectrum of information. One problem with simply making more information available in rural areas is that the rural poor are generally illiterates or without much formal education. and their ability to take advantage of new information may be limited. However with the spread of the nonprint mass media, such as radio and television. information can be made more accessible in verbal and audiovisual-based messages, instead of those coded in printed language. Also their is the possibility of substituting education for expensive agricultural extension services in rural areas. Although agricultural productivity could be significantly improved by the regular visits of an extension agent to farmers, but when the agent can visit only a small fraction of the potential clientele, as it often happens, radio might provide the information more widely. In health or nutrition education, information vital for preventive medicine may be substituted for health educators, who are in chronic short supply. The same analysis can be made for nutrition, education, and community development.

As a support to field agents, information in the form of non-formal didactic messages appropriately organized and presented, can supplement a poorly trained group leader or field 
agent. This is especially true in educational programmes where a teacher's skills may be limited, yet the teacher can guide the students in a form of self-education that can be quite effective.

\section{DESIGNING SOCIAL DEVELOPMENT MESSAGES}

The goal of social mobilization is social change which invariably leads to social development.

While social change is desirable, social development messages such as that of family planning, anti-corruption campaigns or even higher social expectations and the practice of basic hygiene to the target audience, can be designed bearing the following factors in mind.

(i) Use of Acceptable Language: Awareness for any initiated social action project must be created through the use of the predominant local language of the target audience. According to Nwuneli (1985) an audience invariably prefers his local language to any high sounding English or French language. Since one does not wish to impress. but to reach and convince the people. these foreign languages tend to alienate large numbers of people.

(ii) Use of Accessible Channels: The use of inaccessible channels to transfer social action programmes, has been one of the greatest problems confronting social development in the African region. All along. the tendency has been to use modern mass media to create awareness and conducive attitudinal changes on the part of the audience. The evidences available suggest that the modern mass media in Africa are still very much an urban affair (Onabajo, 2002; Opubor, 1985). Similarly. the content of the mass media is presently directed to this urban population. African urban dwellers are on the average more literate, have higher incomes, better living accommodations and more health facilities available, compared to their rural counterparts who constitute over $70 \%$ of the population of any given African nation (Onabajo, 2002). This notwithstanding, mass communication effects studies (Klapper, 1960) suggest that mass media can only spread awareness of any social action programme, nothing more. This means then that if one anticipates a major attitudinal change in favour of a social development programme, interpersonal channels of communication such as faceto-face communication situation, must be initiated to complement the modern mass media and even some folkmedia channels.

(iii) Information and Social Reality: Any information or social action programme. no matter how beneficial. stands a risk of being rejected. if it fails to conform to the social realities of the target population, in terms of their aspirations and perceptions in life. For example in 1975. the Nigerian government imported chilled beef from Bulgaria to sell at highly subsidized rate to supplement the protein intake of low income Nigerians in the cities. According to Nwuneli (1985) the beef was rejected by most working class Nigerians who needed the beef most, because they preferred tough meat, which takes longer time to chew and therefore lasts longer. The government did not take into account the feeding bahaviour patterns of the working class before choosing the quality and type of beef to be imported into the country, which led to the failure of the programme.

It is common knowledge that social development programmes in the African region are often initiated at the highest level of government without reference to the target population. Instructions to execute the programme are then passed down to the common man, who might not be interested in the said programme. When new programmes start by first collecting base line data on the target population, rather than by plunging immediately into action, later evaluations indicate that such programmes survive better than their counterparts lacking any information on the life expectations and ambitions of the target audience.

Opubor (1985), indicates that in situations where social action programmes provide no options or alternatives, the people are often compelled to adopt the change. For example when Nigeria changed from its old currency to a new one, people did not have any choice or alternatives in dealing with the innovation.

(iv) Information and Individual Participation: In discussing social development programmes in Africa, the area least explored and yet 
the most important for the successful execution of various programmes, is the participation of the people. When Africa wanted independence in the early sixties, she went to the grassroots; town and village organizational groups were formed. They were fed constantly with information and the necessary delivery support systems for the execution of the political campaigns set up. The villagers were encouraged to take initiative. They composed songs, coined slogans, put up plays, spoke the language of the people in their dialectic variations. and they achieved results. Political parties still use this strategy today for their political programmes. In addition. they have formed youth and women's wings charged with preaching the ideology of the party.

Since the information given above is common knowledge, the question then is, why have we failed so badly in getting our social development programmes such as family planning, and agricultural innovations to the people? One possible answer to this question. is that we have taken the posture that we do not really need to convince the people. We believe that the people know what is good for them and need not be begged to accept an innovation.

The second reason for this inherent failure. is an extension of the first. Since we have taken the posture that we need not talk the people into accepting anything, we have not bothered to effectively organize the people in any meaningful and result yielding small groups. Instead we have been content to stay many miles away from the grassroots and attempt to communicate with them through the electromagnetic waves and the printed pages to which most of them have little access. May be our reliance on the modern mass media. as the primary means of imparting develop-ment programmes, is due to our holding on to the western model for development support communication.

However, government mobilization efforts in some parts of Africa are noticeable in the areas of Regional Integrated Rural Development land reforms and co-operative development. According to Kassam (1978), the Regional Inte-grated Rural Development has two approaches.

(a) Those that are undertaken mainly on the initiative of donor agencies and subsequently planned and administered by a large expatriate staff. Examples include the Lilongwe Land Development Programme in Ghana.

(b) Those undertaken with substantial initia- tive and participation by National governments as in Ujaama of Tanzania.

The Ujaama village in Tanzania bring to mind the lofty ideas of village-co-operatives. So also are the "Nuoboa" groups in Ghana and the "Isusu" societies in Nigeria.

It is thus desirable that in any social development campaign. individuals from the target population should be able to identify the problem areas and develop appropriate messages for inducing the desired social change

Though the African mass media have grown since independence without ideology, or any systematic calculated strategy. UNESCO data show that Africa is still one of the lowest, in the issue of access to various mass media by its population. Even when the mass media are available. they are concentrated mainly in the urban centers of the various African countries. But the few available have shown that people with high socio-economic status, make use of radio. television and newspapers respectively for information, while people in the low socioeconomic status make use of radio and word-ofmouth communication for information. Similarly information available suggests that radio is very effective in creating the initial awareness for any social action campaign.

\section{COMMUNICATION TRAINING MODELS}

McAnany (1973) lists five strategies which can be adapted to our own training models.

(i) Open Broadcasting: In this model. there is the lack of interaction between producers and consumers of programmes before programmes are planned, produced and broadcast. This is mainly because of the cultural. social and knowledge gaps between the usually urban, educated producers and the illiterate rural consumers. Production is therefore usually based on the vague notion that people want the studio-decided materials that are broadcast. Also, programmes are devised with little or no consultation with specialist agencies who are close to the people and to the government, and with virtually no coordination between them and communication specialists. who may have professional experience and theoretical frame-work on which to base meaningful practice. The result is that programmes are generally produced on perceived or assumed knowledge both of the subject-matter and of the environmental conditions of the 
audience. And thirdly, and perhaps more importantly, there is, by the nature of the strategy, no guidance at the reception level. With no consultation and co-ordination between broadcasters and educational and development agencies, and with no interaction between producers and consumers of programmes, the best one can expect from the Open Broadcast strategy is limited success. This strategy is, unfortunately, the one being used by Nigeria's broadcasting organizations in their limited efforts of broadcasting to the rural population. According to Oso (2002), weekly magazine programmes. farming hints, daily news, health talks and cultural programmes are planned and produced by producers as they see fit, sometimes with the help of urban-oriented members of the public whose experience and understanding of the rural situation are quite different from those of the population for whom these programmes are meant.

(ii) Radio Study Groups: This is the strategy used in Tanzania to teach practical skills. cooperative and civic responsibility to rural communities. Using the strategy requires much more than mere broadcasting. It requires a structure for organizing listening and learning practices, support materials. monitors or teachers. and some kind of assessment. One very important aspect of the strategy is that reception infrastructure is an integral part of the process.

Tanzania uses this strategy as part of a total national plan to develop the people's awareness. their spirit of nationalism and co-operation, and to strengthen their sense of integrity, and bring about defined changes in the people's behaviour and attitudes and in their physical environment. Radio is used in conjunction with the printed word. and they complement each other. Before broadcasts. texts on the subject-matter for study are distributed to the audience. Paraphrased versions of the text materials form the content of broadcast materials.

In utilizing this strategy, Tanzania employs the mass campaign approach to education. Thus, attention is paid to the whole nation, but with particular reference to the rural population. All activities directed towards making a success of the campaign are centralized. Text materials. as well as radio materials paraphrased from them are. of course, of a general nature, so that they can have general application to the entire population. But study groups of between 15 and 30 members are formed in many areas to enable people learn together, as well as to bring a local touch to the general topics discussed. These groups which are usually under the guidance of trained advisers, meet on agreed dates and times that coincide with the radio broadcasts. The task of the adviser or chairman, who is supposed to be a first-among equals and not a teacher or a dictator, is to see that no one dominates the discussion at meetings while the rest kept silent and passive. The emphasis is on complete and equal participation of all group members in exploring the relevance and importance of information distributed by air and print to each group's situation. The combination of these two media-radio and printed material - cannot but have an enhancing effect on learning. Radio enables the study group members to identify themselves with the speakers as well as to refresh their memory, while the written materials are always there for reference. The use of radio also enables the illiterate members of the study groups to get facts and figures about subject-matter for discussion issues.

(iii) Radio Rural Forum: Radio Rural Forum is the strategy which makes use of radio with discussion and decision for rural groups. The strategy involves the presentation of a regular weekly 15-to-30-minutes magazine programme to rural audiences formed into listening groups. The programmes usually comprise rural news, ans-wers to listeners' questions, family advice, a talk and discussion. The groups - usually between ten and thirty listeners each, listen to the progra-mmes and discuss their contents under the guidance of a group leader and then take deci-sions on the points raised. The leader sends monthly reports to the source of the programme for review and possible inclusion in subsequent programmes. The strategy makes an extensive use of audience reaction. where possible, for subsequent programmes. Because of this. there is usually the temptation for broadcasters to work on their own without co-operation with other change agents around in the rural area.

This strategy has a number of advantages:

(a) It evokes a sense of involvement in the rural man as a result of its demand for some actiondecision by the group after discussion. This is a great asset in development. The follow-up of a radio message with localized discussion and decision ensures commitment to agreed actions 
and consequently to social change. Membership of groups exposes the participants to information important to the rural communities, and thus turns such individuals into opinion leaders whose views would tend to be respected in the community. This is one aspect of the radiation effect of Radio Rural Forums. The other is that those who are non-participants could still listen to the radio messages, and probably be affected by them. The interplay of these two advantages cannot but have a salutary effect on the quantity and quality of developmental information available within the community.

(a) Forums send back reports and messages in which group members express their views and opinions, thus providing the vital feedback which is often missing in mass media activities.

(b) The forum strategy is based on the conviction that rural development must essentially come from the rural people themselves. and not be dropped from above.The in-built localized discussion and decisions ensure that the rural community is put in a position whereby it can be both the subject and object of development.

(iv) Radio Schools: This is the most widespread strategy for using radio for rural community education in Latin America. It was originally tried at Sutatenza, Colombia, where it has now permeated the life of the rural population. The 'schools' are small organized listening/ learning groups meeting in houses or churches under a guide. The audience of these radio 'schools' is primarily illiterate rural adults. The basic aim of this strategy is to offer fundamental, integral education which goes beyond mere reading, writing and cognitive skills and tries to change the passive and dependent attitude of the rural man, creating a deepening of his sense of dignity and self-worth and turning him into a new man (Hall, 1981).

The approach is basically multi-media, employing at least radio and printed booklets almost everywhere, but also frequently adding newspapers, charts, booklets, film strips and traditional teaching/learning methods. The 'schools' are based on the principle of homophily, so that group members not only know each other, but largely have identical perception of the world and of their own environment. Outreach staff act as supervisors, co-ordinating activities. distributing material, and visiting groups from time to time in order to encourage them.

Radio 'Schools' have been successful in arousing the rural people to action, precisely because it identifies with the rural population and its problems. The radio schools foster greater knowledge of the real needs of rural areas by having a significant number of rural leadership in the organization of its activities. ensuring real contact of policy-makers with rural people and their problems, and enabling functional feedback to flow from the audiences. In addition. the radio schools are basically listening/learning groups, with the advantages of group listening and of local monitors and supervisors. The solidarity of the group encourages perseverance in pursuing group goals, and visits from supervisors create a sense of identity. Perhaps. the one peculiar aspect of this strategy is the fact that the activities are a continuing process $-\mathrm{a}$ factor which makes radio and the 'schools' part of everyday life of the people.

(v) Radio and Animation: This is also known as the Radio Participating Group; it aims at promoting among local communities a trained cadre of decision leaders. The strategy is used to train leaders whose role is to promote, in a non-directive way, a dialogue in which community members participate in defining their development problems, putting them in a wider social context and devising ways to mobilize their people to common action. The strategy places emphasis on radio defining, and not suggesting solutions to the people's problems. Radio programmes are made from recorded responses to a definite problem given by some members of the listening public. The participating groups then listen to these responses and views, discuss the problem further, thus creating avenues for further response from the public, and sub-sequently eliciting decisions.

The assumptions of this strategy are:

(a) That no solutions to problems can be imposed on local communities from the outside. The local communities must first arrive at the problem definition and then its solution on their own;

(b) That the social animator is to be as closely identified with the local community as possible

(c) That the purpose of information in this approach is to help to define the problem and not give the solutions; and

(d) That community participation and social action is the goal. and therefore feedback from the community is essential.

\section{THE APPROPRIATE STRATEGY}

In planning and implementing effective social 
mobilization, it is necessary to take into consideration the following:

i. A decision should be taken on the type of campaign that is to be implemented. Any campaign adopted must result in direct action to improve the lives of the recipients of such campaigns and its objectives should be properly articulated and stated.

ii. It will be necessary to define the nature and number of group members that will be included in the scheme.

iii. In order to achieve a mass campaign, every opportunity to publicize the activity should be seized; states and national broadcast stations should be made to air jingles aimed at publicizing the programme. Also newspapers and magazines should advertise the programme as well as carry special supplements on the programme.

iv. Study-group leaders should be selected and this should depend to a great extent on the area and the approach of the local adult education field staff. Also leaders of the community development associations can also be adopted depending on their relevance to the social mobilization programme on hand. Another option is to advertise for such leaders and screen them

v. Selected group leaders should go through a process of training at the local government level and these leaders will be expected to train other leaders at the district and community levels.

vi. The campaign must lay emphasis on action by the groups both individually and commercially. This method encourages groups of people to identify a local problem through discussion and to proffer solution to the problem.

vii. An evaluation mechanism should be built into the mobilization to assess the various stages of the campaign. The amount of knowledge gained should be determined by a pre and post test of participants in a sample of groups.

viii. Any mobilization campaign should employ the multi-media campaign approach comprising of radio, television, newspapers, posters, the cinema van. and interpersonal communication. for it to be effective.

\section{CONCLUSION}

The communication models discussed have proved their worth for several competing reasons. They are very effective in reaching large numbers of people in rural areas who have previously not been reached by either formal education or traditional adult education approaches. The radio is nearly always a first investment in rural area once cash surplus begins to appear in the economy. As an educational approach, it offers a realistic alternative to traditional teacher-student relationships which have been discussed by numerous educators including Paulo Freire Mwalimu Julius Nyerere and Ivan Illich (Hall, 1981). The emphasis on radio study groups is on complete and equal participation of all group members in exploring the relevance and importance of the information distributed by air and print to the reality of each group's existence. This joint exploration results in creation of knowledge which has existential meaning for each and everyone of the people involved.

Additionally, the method has particular relevance for Nigeria in that any development strategy depends on the people's involvement in the discussion of the development plans which will consequently affect their lives. If development is to benefit the people. the people must participate in the planning of their own development. After years of colonial education patterns. which have emphasized the position of the teacher as the possessor of knowledge and the students as receivers of knowledge, the traditional African concepts of discussion until agreement is reached have been weakened. The radio study group method is a workable alternative.

Still another result of the experience to date is the fact that the method is extremely flexible regarding what can be taught and under what conditions the groups can operate. It can be used to cover mobilization campaigns in political execution, health, agricultural methods and nutrition.

\section{REFERENCES}

Akeredolu-Ale, E.O. (ed.). 1993. Mass Media and Rural Development in Nigeria. Ibadan: Spectrum Books Ltd.

Clarke, K. 2001. "What Does it Mean". Development Issue, 16 (4): 16 - 25

Hall, B. L. 1981 "Mass Communication and Adult Education", (pp 215 - 231) in L. Bown and J. T. Okelara (eds.), An Introduction to the Study of Adult Education. Ibadan: University Press Ltd.

Kassam, Y.O. 1978. The Adult Education Revolution in Tanzania. Nairobi: Shungwaya Publishers Ltd. 
Klapper, T.J. 1960. The Effects of Mass Communication. Illinois: Free Press, Glencoe.

Koinyan, L.D. 1993 "Preliminary Remarks by Chairman of DFFRI", (pp. 42 - 48) in E. O. Akeredolu-Ale (ed.), Mass Media and Rural Development in Nigeria. Ibadan Spectrum Books Ltd.

McAnany, E.G. 1973 "Radio's Role in Development: Five. Strategies of Use". Information Bulleting, 4: 62 - 80. Washington D.C: Information Centre on Institution Technology.

Nwuneli, O. (ed.). 1985. Mass Communication in Nigeria: A Book of Reading. Enugu: Fourth Dimension Publishing Company Inc.

Okafor, O. 2003. "Mobilization of the Nigerian Masses for . Peaceful Elections: Role of Mass Media and Communication Practitioners", (pp. 104 - 120) in I. E. Nwosu (ed.), Polimedia - Media and Politics in Nigeria. Enugu: Prime Targets Ltd.
Onabajo, O. 2002. Elements of Rural Broadcasting. Lagos: Gabi Concept Ltd.

Opubor, A. 1985. "Mass Communication and Modern Development in Nigeria", (pp. $154-171$ ) in O. Nwuneli (ed.), Mass Communication in Nigeria: A Book of Reading. Enugu: Fourth Dimension Publishing Company Inc.

Oso, L. 2002. "Radio for Community Development", (pp. 153 - 169) in L. Oso (ed.), Communication and Development - A Reader: Abeokuta: Jedidiah Publishers.

Resengnen, K. C. 2000. Communication An Introduction. London: SAGE Publications.

Umar, M. M. 2003. "Significance of Participatory Communication in Non-formal Political Education in Northern Zaria" The Nigerian Journal of Communications, 2(2): 1-7. 